\title{
Labially Positioned Rudimentary Mesiodens - A Case Report
}

\author{
Tayab T'1, Kayalvizhi $\mathbf{G}^{2}$
}

\begin{abstract}
This is a case report that describes a labially positioned rudimentary mesiodens in between the fully erupted maxillary central incisors in a 10-year-old girl. It was partially erupted in the oral cavity, without causing malocclusion or displacement of adjacent teeth. The clinical and radiographic appearance and therapeutic considerations are presented. The diverse modes of presentation of this common dental anomaly are described in this case report to alert the clinician.
\end{abstract}

Key words: Supernumerary, Hyperdontia, Rudimentary, Mesio-dens

${ }^{1}$ Ex Senior Lecturer

Department of Pedodontics \& Preventive Dentistry

M.R Ambedkar Dental College, Bangalore,

Karnataka, India

${ }^{2}$ Associate Professor

Department of Pedodontics \& Preventive Dentistry

Indira Gandhi Institute of Dental

Sciences,Puducherry,

India

\section{Contact Autbor \\ Dr Tabassum Tayab drtabassum2001@yahoo.co.in}

J Oral Health Comm Dent 2013;7(3)178-180

\section{INTRODUCTION \\ T Typerdontia/Supernumerary teeth

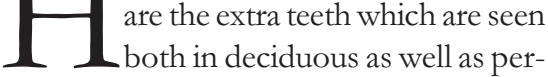 manent dentition and may have either erupted or are impacted (1). These dental anomalies may be manifested as an iso- lated defect or as part of a medical syn- drome such as cleidocranial dysplasia and Gardner syndrome. A supernumerary tooth located in the maxillary central inci- sor region is a mesiodens; with an overall prevalence of $1 \%$ to $2 \%$ in Caucasian populations (2).}

The etiology of supernumerary teeth is considered to be multi-factorial comprising of environmental and genetic components. Hyperactivity of the dental lamina is the result of an environmental influence. Autosomal dominant inheritance with incomplete penetration has been the proposed genetic theory. A sex-linked pattern has also been proposed as males are affected thrice as frequently as females (3). This case report describes the diverse modes of presentation of this common dental anomaly.

\section{CASE REPORT}

A 10-year-old girl was referred to Department of Pedodontics, MR Ambedkar Dental College. Her medical and family his- tory was noncontributory. General and dental development was normal for her chronologic age. The reason for referral was the presence of an over retained deciduous central incisor labially positioned to the erupted permanent maxillary central incisors and was advised to undergo extraction of the same. The child also complained of mild pain in upper anterior region for the past one month due to the over retained deciduous central incisor. No significant abnormality was noted on extraoral examination.

Intra-oral examination revealed a mixed dentition with good oral health. The anterior teeth were not crowded and were completely erupted. A rudimentary crown form projecting from the labial surface between the fully erupted permanent maxillary central incisors was noted. Intra-oral periapical radiograph of the maxillary anterior region showed a tiny mesiodens with a completely formed crown and root positioned in the midline labially to the roots of the permanent central incisors. Root development of the maxillary permanent central and lateral incisors was completed. The mesiodens was not visible in the anterior occlusal view suggestive of its labial position. The mesiodens was extracted under local anesthesia and no further treatment was required. (Figure 1-4) 


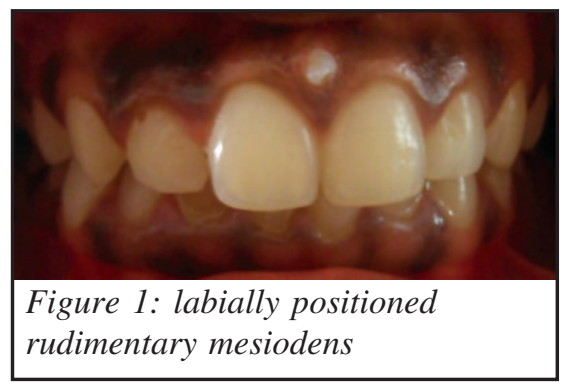

\section{DISCUSSION}

Supernumerary teeth may be classified according to morphology, shape and location. Their morphology is usually normal or conical in the primary dentition but is more variable in the permanent dentition. Primosch classified supernumeraries into two types according to their shape: supplemental and rudimentary. Supplemental (or eumorphic) refers to supernumerary teeth of normal shape and size, and may also be termed incisiform. Rudimentary (or dysmorphic) defines teeth of abnormal shape and smaller size. According to the morphology they are classified as conical/ peg-shaped, tuberculated or molariform $(3,4)$. Furthermore supernumeraries may also be categorized into three types according to their locations as mesiodens, paramolar and distomolar.

Conical mesiodens occur singly and are usually located palatally or between the maxillary central incisors, tending to displace the erupting permanent central incisors (5). They have fully formed roots and usually erupt into the oral cavity or remain impacted or erupt in an inverted positioned $(1,3)$. Von Arx reported that majority of supernumerary teeth lay palatal to the central incisors (6). Asaumi JI et al. evaluated 147 mesiodens by axial radiography and found that $89 \%$ were located palatally against the dental arch, 11\% overlapped the dental arch and none were placed labially (7). In our case a single tooth, smaller in size that had erupted labial to the permanent maxillary central incisors and positioned in the midline with fully formed root was diagnosed as a conical rudimentary mesiodens.

Supernumerary teeth may develop in the direction of normal eruption, appear in-

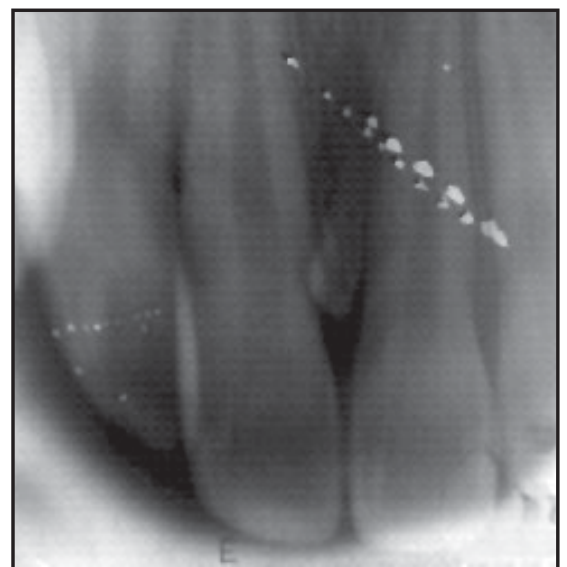

Figure 2: IOPA $x$-ray revealing presence of mesiodens in between the permanent maxillary central incisors

verted, transverse, assume an ectopic position, or follow an abnormal path of eruption. Tay et al. observed that $16 \cdot 8 \%$ of supernumerary teeth were normally-orientated, $77 \cdot 6 \%$ were inverted and $5.6 \%$ were transverse in relation to the permanent teeth (8). Detection of these accessory teeth may be fairly obvious, either because of patient's complaint or on clinical examination. Mesiodens are usually not associated with other developmental anomalies in the oral cavity apart from local effects, such as delayed or asymmetrical path of eruption of permanent incisors, crowding, spacing, and impaction of permanent incisors, median diastema, or cystic lesions. Hence diagnosing this case presented a dilemma as the mesiodens did not affect the adjacent permanent teeth. In addition, due to its labial position and small size it was mistaken for an over retained deciduous primary tooth (9). Although in the present case the mesiodens did not impede the eruption of the adjacent permanent teeth and was not associated with any pathological condition or syndrome it was extracted as it caused discomfort to the patient.

It is possible that a mesiodens is found during a routine radiographic check-up without significant effect on the adjacent teeth. Panoramic, maxillary occlusal and periapical radiographs are indicated to assist in the diagnosis of mesiodens. Although a maxillary occlusal view is recom-
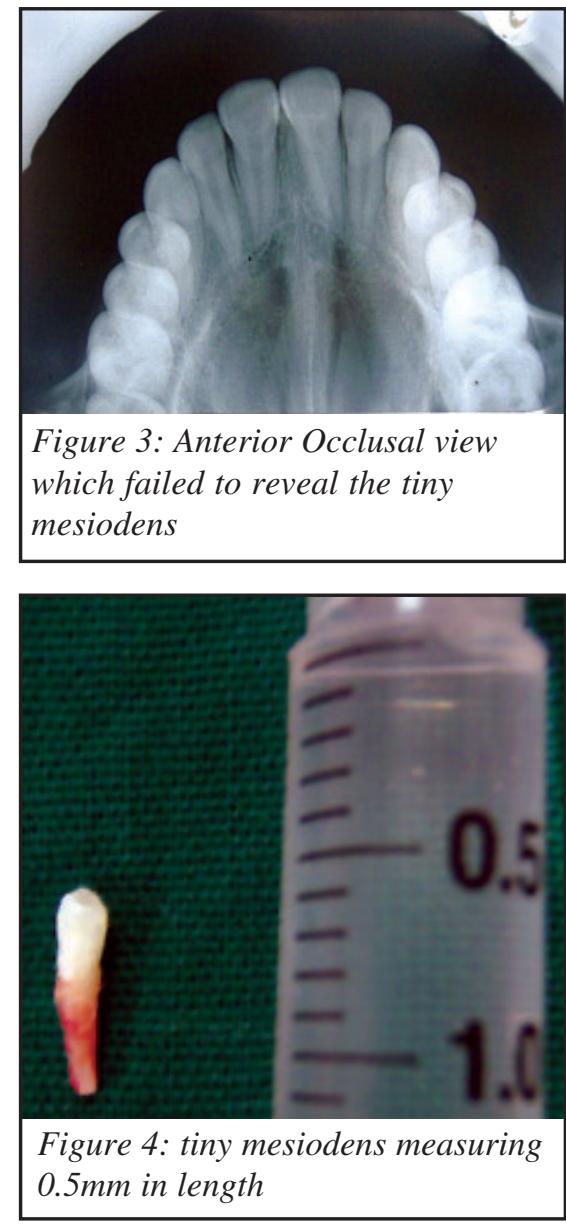

mended as a screening aid and provides additional information about the position and shape of the mesiodens in the present case it failed to offer any evidence due to its labial position. In such cases the buccolingual position of the unerupted supernumerary can be located using the parallax technique (10).

\section{CONCLUSION}

Although the mesiodens is a fairly common dental anomaly, there are various modes of its presentation. It is therefore important for the clinician to diagnose a mesiodens based on the following factors: eruption status (erupted, impacted), morphology, position of mesiodens in the arch (palatal, labial or in between), orientation (vertical, horizontal or inverted), number of teeth (single, double or multiple) and type of dentition. Management usually involves extraction of the mesiodens followed by orthodontic treatment if the adjacent teeth are affected. 


\section{REFERENCES}

1. Russell KA, Folwarczna MA. Mesiodens - Diagnosis and Management of a Common Supernumerary Tooth. J Can Dent Assoc 2003;69(6):362-66.

2. Luten JR. The prevalence of supernumerary teeth in primary and mixed dentitions. J Dent Child 1967;34(5):346-53.

3. Primosch RE. Anterior supernumerary teeth - assessment and surgical intervention in children. Pediatr Dent 1981;3(2):204-15.

4. Foster TD, Taylor GS. Characteristics of supernumerary teeth in the upper central incisor region. Dent Pract Dent Rec 1969;20(1):8-12.

5. Hattab FN, Yassin OM, Rawashdeh MA. Supernumerary teeth: report of three cases and review of the literature. ASDC J Dent Child 1994;61(5-6):38293.

6. von Arx T. Anterior maxillary supernumerary teeth: a clinical and radiographic study. Aust Dent $J$ 1992;37: 189-95.

7. Asaumi JI, Shibita Y, Yangi Y, Hisatomi M, Matsuzaki $\mathrm{H}$, Konouchi $\mathrm{H}$, et al.
Radiographic examination of mesiodens and their associated complications. Dentomaxillofac Radiol 2004;33:125 27.

8. Tay F, Pang A, Yuen S. Unerupted maxillary anterior supernumerary teeth: report of 204 cases. ASDC J Dent Child 1984;51:189-94.

9. Meighani G, Pakdaman A. Diagnosis and Management of Supernumerary (Mesiodens): A Review of the Literature. $J$ Dent 2010;7(1):41-49.

10. Henry RJ, Post AC. A labially positioned mesiodens: case report. Pediatr Dent 1989;11(1):59-63. 